\title{
Smoking strongly predicts disability retirement due to COPD: the Finnish Twin Cohort Study
}

\author{
K. Koskenvuo*,\#, U. Broms", , T. Korhonen\#, , L.A. Laitinen+, A. Huunan-Seppälä ${ }^{\S}$, \\ T. Keistinen ${ }^{f}$, I. Autti-Rämö*, J. Kaprio ${ }^{\top, * *}$ and M. Koskenvuo ${ }^{\#}$
}

ABSTRACT: No previous studies on the association of smoking behaviour with disability retirement due to register verified chronic obstructive pulmonary disease (COPD) exist. This 30-yr follow-up study examined how strongly aspects of cigarette smoking predict disability retirement due to COPD.

The study population consisted of 24,043 adult Finnish twins $(49.7 \%$ females) followed from 1975 to 2004. At baseline the participants had responded to a questionnaire. Information on retirement was obtained from the Finnish pension registers.

Smoking strongly predicted disability retirement due to COPD. In comparison to neversmokers, age adjusted hazard ratio (HR) for current smokers was $22.0(95 \% \mathrm{Cl} 10.0-48.5)$ and for smokers with $\geqslant 12$ pack-yrs was $27.3(95 \% \mathrm{Cl} 12.6-59.5)$. Similar estimates of risk were observed in within-pair analyses of twin pairs discordant for disability retirement due to COPD. Among discordant monozygotic pairs those with disability pension due to COPD were more often current smokers. The effect of early smoking onset ( $<18 \mathrm{yrs})$ on the risk of disability retirement due to COPD remained after adjustment for the amount smoked (HR 1.70, 95\% $\mathrm{Cl} 1.08-2.68$ ).

Smoking strongly predicts disability retirement due to COPD. Preventive measures against disability retirement and other harmful consequences of tobacco smoking should receive greater emphasis.

KEYWORDS: Chronic obstructive pulmonary disease, disability retirement, smoking behaviour

$\mathrm{t}$ has been estimated that by 2020 chronic obstructive pulmonary disease (COPD) will be

the third leading cause of death and the fifth most common cause of disability in the world [1-4]. The overall prevalence of spirometrically confirmed COPD has been estimated to vary between $4 \%$ and $11 \%[5,6]$. Underdiagnosis of COPD is very common in some countries [7]. Due to the global aging of populations, the burden of COPD will increase in future [8]. Beyond age, smoking is the major risk factor for COPD and the prevalence rates in different countries are related to rates of smoking as well as to the time of initiation of tobacco smoking $[4,9,10]$. Depending on the population studied, other risk factors of lesser importance include air pollution, occupational hazards and infections [8].

Previous studies have shown that smoking is related to increased risk of disability retirement $[11,12]$. Population-based follow-up studies on the impact of COPD on the risk of long-term work disability are lacking. Furthermore, to our knowledge no previous studies on the association of smoking behaviour with disability retirement due to register verified COPD have been carried out. The aim of this 30-yr follow-up study was to examine how strongly different aspects of smoking behaviour (smoking status, life-time amount of smoking and age at initiation of smoking) predict disability retirement due to COPD.

\section{METHODS}

\section{Data}

The ethical committee of the University of Helsinki, Finland has approved the study. The data were derived from the Finnish Twin Cohort Study [13]. Based on the previous research, twins have been shown to represent the overall population well. For example, the levels of major risk factors, such as smoking, and the standardised cancer incidence ratio do not differ between twins and singletons [14, 15]. A baseline questionnaire in 1975 was used to collect information on health and health-related factors, including a detailed smoking history. The overall
AFFILIATIONS

*Social Insurance Institution of Finland,

\#Dept of Public Health, University of Helsinki,

'Dept of Mental Health and Alcohol Abuse Services, National Institute for Health and Welfare,

+Dept of Medicine, Helsinki

University Central Hospital,

${ }^{f}$ Ministry of Social Affairs and Health,

${ }^{*}$ Dept of Public Health and Institute for Molecular Medicine, University of Helsinki, Helsinki, and

${ }^{\text {s}}$ Dept of General Practice, University of Tampere, Tampere, Finland.

\section{CORRESPONDENCE}

K. Koskenvuo

Social Insurance Institution of Finland Research Dept

P.0. Box. 450

00101 Helsinki

Finland

E-mail: karoliina.koskenvuo@kela.fi

Received:

Jan 182010

Accepted after revision:

April 282010

First published online:

June 012010

Online ISSN 1399-3003 
response rate was $89 \%$. The same-sex twins born before 1958 and alive in 1974 were ascertained from the Central Population Register of Finland. Zygosity was determined by questions on similarity of physical appearance at school age classifying $93 \%$ of pairs as monozygotic or dizygotic twins (the probability of misclassification of a twin pair was 1.7\%) [16]. Information on mortality and migration was updated regularly from the Central Population Register.

\section{Disability retirement due to COPD}

The granting of a disability pension (either disability pension for persons aged 16-64 yrs or individual early retirement pension for employees aged 58-64 yrs, which was abolished in 2005) requires the presence of a medically confirmed illness, disease or injury, which essentially restricts or prevents working. Disability pension is granted to an employee when his/her work capacity is assessed to have been reduced by at least $60 \%$, for $\geqslant 12$ months.

According to the Finnish Current Care Guideline, which is in line with the international guidelines for the diagnosis and treatment of COPD (Global Initiative for Chronic Obstructive Lung Disease, American Thoracic Society/European Respiratory Society) [17-19] and to the established practice of the insurance institutions, the medical certificate issued by the treating physician must contain information about the medical status, including the COPD stages (mild, moderate, severe or very severe), the pulmonary function indices and the effect of medication. This information must also be included in the final decision which the insurance institution, taking into account the statement of the insurance physician, issues on a person's work disability.

All persons who have been granted a disability pension due to COPD have been either treated in a specialised in-patient care facility and/or have mainly been treated by specialists and are entitled to a $75 \%$ reimbursement of pharmaceutical expenses from the Social Insurance Institution of Finland. Patients whose forced expiratory volume in $1 \mathrm{~s}$ is $<30 \%$ or $<1 \mathrm{~L}$ are, under all circumstances, incapable of doing any physical work. In addition, increased carbon dioxide retention (arterial carbon dioxide tension $>6.6 \mathrm{kPa}$ ) or significant hypoxia (arterial oxygen tension $<8 \mathrm{kPa}$ ) indicate work disability [20].

Information on retirement events during the follow-up, including diagnoses (International Classification of Diseases, ICD-8/9 and 10th revisions), was obtained from the Social Insurance Institution and the Finnish Centre for Pensions. COPD diagnoses registered by insurance and pension institutions as part of their decision making process were encoded using ICD-8, ICD-9 and ICD-10. The selected ICD-8/9 diagnoses were: 490 (bronchitis, not specified as acute or chronic), 491 (chronic bronchitis), 492 (emphysema) and 496 (chronic airway obstruction, not elsewhere classified), while the selected ICD-10 diagnoses comprised the following: J40 (bronchitis, not specified as acute or chronic), J41 (simple and mucopurulent chronic bronchitis), J42 (unspecified chronic bronchitis), J43 (emphysema) and J44 (other chronic obstructive pulmonary disease).

No significant social or pension legislative changes in the disability criteria were made during the follow-up period of this study. The record linkage was performed by using the unique person numbers assigned to all Finnish citizens.

For the purposes of this study those who were retired at the time of the first survey questionnaire in 1975 were excluded. Detailed data descriptions are included in the previous study on the contribution of genetic factors to disability retirement [21]. The study sample of this study consisted of 24,043 participants $(49.7 \%$ females, mean age at baseline assessment $32.7 \pm 12$ yrs) consisting of 11,186 complete same-sex twin pairs including 3,519 monozygotic and 7,667 dizygotic pairs and 1,671 twin individuals of incomplete pairs, who were followed up from the beginning of 1975 to the date of disability retirement, the date when the person began to receive an old age pension, the date of death, the date of emigration or until the end of 2004. The 30-yr cumulative incidence of disability retirement (all causes) was 20\% (4,894 subjects) [21].

\section{Smoking behaviour}

Smoking behaviour was measured in 1975 by a detailed set of questions, which were then used to define smoking status, age at smoking initiation and cumulative history of cigarette smoking. Smoking status was divided into four classes: never-smokers, occasional smokers, former smokers and current smokers. Current smokers comprised those who had smoked five to 10 packs of cigarettes over their lifetime and who were smoking regularly (daily or almost daily) at the time of the study. Persons who had smoked $>100$ cigarettes (five packs), but were not regular smokers were considered occasional smokers, while former smokers were regular smokers who reported no longer smoking [22, 23].

Age at smoking initiation was defined as the age when the participants reported having started regular smoking, and dichotomised as two categories: $<18 / \geqslant 18$ yrs. Former smokers were asked at what age they had quit. Both former and current smokers were asked how much they typically smoked daily. Cumulative smoking was estimated as "pack-yrs" (number of cigarettes smoked per day $\times$ number of yrs smoked/20). For purposes of analysis this was classified using the following categories: $0,<5,5-11.9$ and $\geqslant 12$, never-smokers comprising the reference category (0). The upper cut-point was set at 12 (i.e. the median pack-yr value among those with $\geqslant 5$ pack-yrs).

As hard physical work has been shown to increase the risk of disability retirement [24], its possible confounding effect was tested. Asked about physical activity at work, the participants were invited to choose among the following alternatives: $1=$ mainly sedentary work which requires very little physical activity; 2 =work which involves standing and walking, but no other physical activity; $3=$ work which in addition to standing and walking requires lifting and carrying; $4=$ heavy physical activity.

\section{Statistical methods}

The association between smoking behaviour and disability retirement due to COPD was analysed using Cox regression. Due to low numbers of females with disability pension because of COPD $(n=16)$, males and females were pooled together in the final analyses. In addition, no statistically significant sex $\times$ smoking interactions were found $(\mathrm{p}=0.23-0.97$, Wald statistics). 
However, the analyses were also made separately for females and males showing similarity.

We report hazard ratios (HR) with 95\% confidence intervals (CI) and show cumulative hazard curves for age at onset of event of interest by smoking behaviour variables. Cox proportional hazard assumptions were tested by visual examination of $-\ln (-\ln ($ survival $))$ curves for each category of a covariate versus $\ln ($ analysis time). The analyses were carried out using the SPSS 17.0 (SPSS Inc., Chicago, IL, USA) and Stata 9.0 (StataCorp., College Station, TX, USA) statistical packages. The robust estimator of variance and the cluster option in Stata were used when estimating the standard errors [25] to take into account the sampling of subjects as twin pairs.

Both smoking [26] and risk of disability pension [21] are influenced by familial and genetic factors, and the association between the two may be confounded by underlying familial factors common to both. In order to control for such familial influences on the association between smoking and disability retirement due to COPD, we exploited the fact that our data consisted of twins. Monozygotic and dizygotic twins are assumed to share the same amount of environmental variation, which is partly shared by a twin pair and partly unique to each twin individual. Monozygotic twins are genetically identical at the sequence level, whereas dizygotic twins share on average $50 \%$ of their segregating genes [27].

Twin pairs discordant for smoking and disability retirement were analysed using a matched-pair case-control design. Twin pairs were regarded as discordant for COPD retirement if one twin had such a retirement event (case) while the co-twin did not (control). Among such pairs, we examined the distribution of smoking behaviour, such as smoking status and pack-yrs. Using conditional logistic regression the significance of the smoking disability retirement due to COPD-association within such pairs was assessed as odds ratios (OR) [28].

To ensure the reliability of the outcome and control status, we checked the diagnosis related to granted disability pensions for those discordant pairs where both twins had retired on disability: one due to COPD and one due to some other medical reason. Only a few twin pairs in which one of the pair had retired early because of COPD and one because of cardiovascular diseases were found. Only a single pair was found in which one twin had retired early because of COPD and one because of asthma.

\section{RESULTS}

Disability pension due to COPD was granted to 107 participants during the follow-up of 24,043 study subjects. The average age of retirement due to COPD was 56.2 (36.764.8) yrs.

The study sample consisted of $47 \%$ never-smokers, $3 \%$ occasional smokers, $16 \%$ former smokers and $34 \%$ current smokers. Of the participants, $26 \%$ were smokers with $<5$ packyrs and $27 \%$ were smokers with $\geqslant 5$ pack-yrs. Almost half $(47 \%)$ of the smokers had started smoking before the age of 18 yrs.

Compared to the risk of never-smokers the HR of disability retirement due to COPD was 22.0 (95\% CI 10.0-48.5) for current smokers and 3.28 (95\% CI 1.19-9.07) for former smokers. No increased risk of disability retirement due to COPD was found for occasional smokers. Regular smokers with 5-11 pack-yrs had a seven-fold greater risk of disability retirement (HR 6.94, 95\% CI 2.60-18.5) compared with neversmokers. The HR of disability retirement due to COPD for smokers with $\geqslant 12$ pack-yrs was 27.3 (95\% CI 12.6-59.5). No increased risk was observed for smokers with $<5$ pack-yrs (HR 0.95, 95\% CI 0.20-4.56) (figs 1 and 2).

Ever smokers who had started to smoke regularly when they were aged $<18$ yrs had two-fold greater risk (HR 2.05, 95\% CI 1.30-3.25) of disability retirement due to COPD compared to those who had started to smoke later (fig. 3). After adjustment for the amount smoked the risk of retirement due to COPD remained 1.7-fold higher among those with early onset of smoking (95\% CI 1.08-2.68). The risk of disability retirement due to COPD according to the age at initiation of smoking was also examined among smokers with $\geqslant 5$ pack-yrs. Those who had started smoking before the age of 18 yrs had a 1.7-fold increased risk (HR 1.67, 95\% CI 1.05-2.64) of disability retirement due to COPD as compared to those smokers who had started to smoke after the age of 18 yrs.

Since hard physical work increased the risk of disability retirement as compared to the risk of those with sedentary work (HR 3.22, 95\% CI 1.77-5.85), the associations of smoking behaviour with the risk of disability retirement due to COPD were adjusted for strenuousness of work, and the risk related to smoking was examined separately for those with hard physical work and those with sedentary work. The association of smoking behaviour with COPD disability pension risk was unchanged in these analyses.

In the within-pair analysis (table 1) we identified 81 pairs discordant for disability retirement due to COPD. Conditional logistic regression models showed that current smoker cotwins had almost a 12 -fold relative risk (OR $11.8,95 \%$ CI $2.04-$ 67.8 ) and co-twins with pack-yrs $\geqslant 12$ had a 22 -fold relative risk (OR 21.8, 95\% CI 1.96-242) for disability retirement due to COPD compared to their co-twins. There were too few monozygotic pairs $(n=13)$ discordant for disability retirement due to COPD to permit a separate within-pair analysis. However, those with disability pension due to COPD were

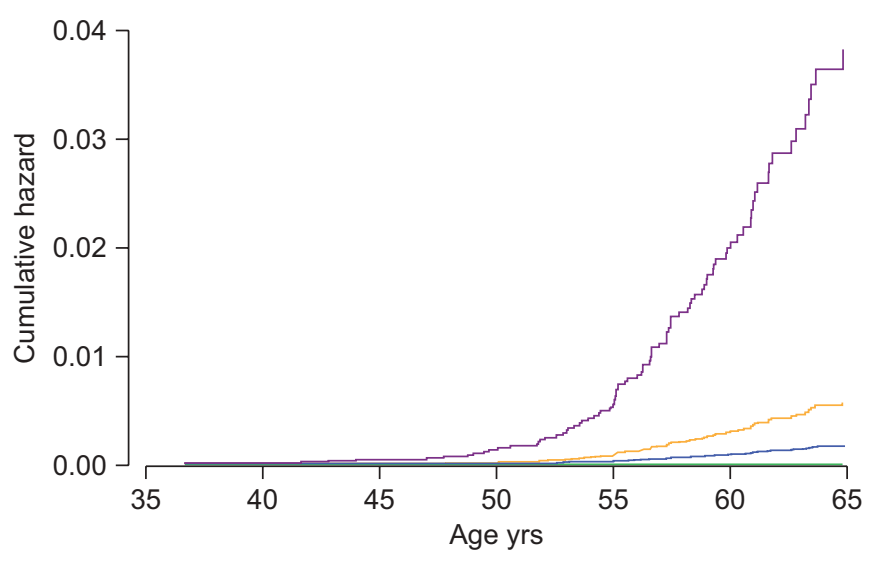

FIGURE 1. Risk of disability retirement due to chronic obstructive pulmonary disease by smoking status: never-smoker (blue line), occasional smoker (green line), former smoker (orange line) and current smoker (purple line). 


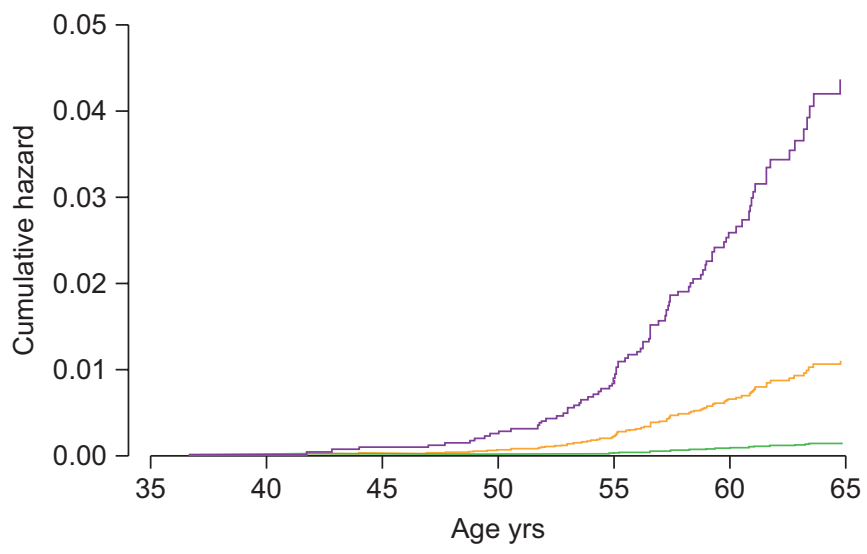

FIGURE 2. Risk of disability retirement due to chronic obstructive pulmonary disease by pack-yrs: reference $0,<5$ pack-yrs (green line), 5 to $<12$ pack-yrs (orange line) and $\geqslant 12$ pack-yrs (purple line)

more often current smokers $(n=10)$ than those without $(n=6)$. Furthermore the number of former smokers and neversmokers was higher among those who were not retired due to COPD.

\section{DISCUSSION}

This 30-yr follow-up study revealed the novel finding that different components of smoking behaviour (life-time amount of smoking and age at initiation of smoking) strongly predict disability retirement due to register verified COPD. In comparison to never-smokers, current smokers had a $>20$ fold increased risk of disability retirement due to COPD, while there was a three-fold increase in risk for former smokers. Increasing exposure to tobacco (as measured by pack-yrs) increased linearly the risk of disability retirement. Among ever smokers early smoking onset was associated with a two-fold higher risk compared to a later onset. Amount smoked and level of smoking correlated with the age at initiation of smoking [29]. Our results showed, however, that even after adjustment for the amount smoked the risk of retirement due to COPD remained higher among those with early onset of smoking. Thus, we consistently demonstrated that smoking in

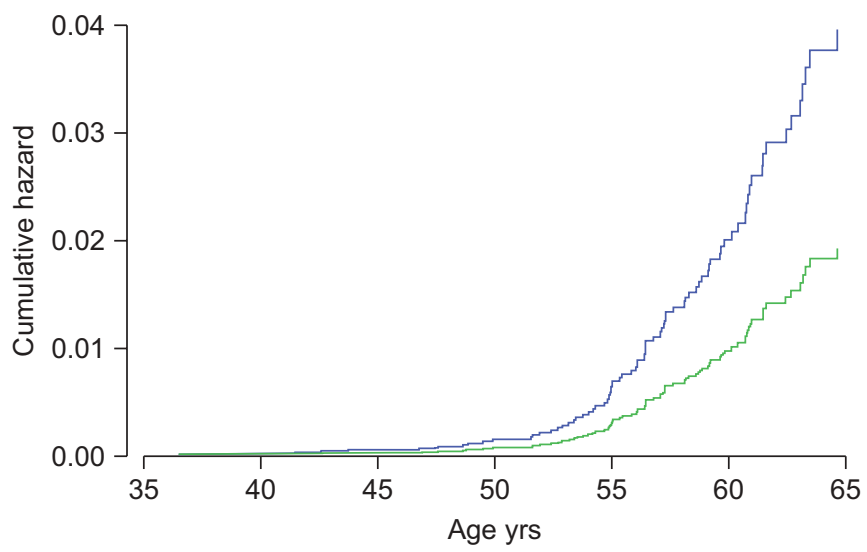

FIGURE 3. Risk of disability retirement due to chronic obstructive pulmonary disease by age at smoking initiation: $<18$ yrs (blue line) and $\geqslant 18$ yrs (green line)

\begin{tabular}{lcc} 
TABLE 1 & $\begin{array}{l}\text { Conditional logistic regression analysis among } \\
\text { all twin pairs discordant for disability retirement } \\
\text { due to chronic obstructive pulmonary disease by } \\
\text { smoking status and pack-yrs }\end{array}$ \\
& \multicolumn{1}{c}{ Pairs $\mathbf{n}$} & OR (95\% Cl) \\
\hline & 63 & \\
\hline $\begin{array}{l}\text { Smoking status } \\
\text { Never }\end{array}$ & & 1.00 \\
$\quad$ Former & & $1.47(0.25-8.45)$ \\
Current & 61 & $11.8(2.04-67.8)$ \\
Pack-yrs & & 1.00 \\
0 & & $1.20(0.07-20.2)$ \\
$<5$ & & $12.3(0.93-162)$ \\
5 to $<12$ & & $21.8(1.96-242)$ \\
$\geqslant 12$ &
\end{tabular}

a dose-response pattern strongly predicts the subsequent risk of disability retirement due to COPD.

The within-pair analysis confirmed the individual level result where current smokers had over a 20-fold increased risk of disability retirement due to COPD compared to neversmokers. Conditional logistic analysis revealed co-twins with $\geqslant 12$ pack-yrs to have a 22 -fold relative risk for disability retirement due to COPD, albeit with rather wide $95 \%$ CI, within similar trends with monozygotic pairs even though the number of discordant monozygotic pairs was modest.

Due to the low number of females with disability retirement due to COPD and no sex $\times$ smoking interaction, we pooled males and females together. It remains a challenge for future studies to investigate whether females are more vulnerable to smoking in terms of our outcome. Concerning COPD, it has been suggested that female smokers may have increased susceptibility, although the mechanism is still unclear [30].

The risk of disability retirement due to COPD was not increased among occasional smokers. However, emerging evidence indicates that not only "active", but also environmental tobacco exposure is related to the development of COPD [31, 32]. In addition, results from the recent study among Finnish adult twins showed an elevated risk of chronic bronchitis also for former and light smokers [33]. One explanation why the risk of disability retirement due to COPD was not increased among occasional smokers may be that disability retirement could be seen as an early end-point granted before the official old age pension, which requires considerable decrease in work ability and hence advanced COPD.

A strength of this study is the large study sample with a high initial response rate $(89 \%)$. In addition, loss to follow-up is minimal or none since almost all subjects could be traced through comprehensive and reliable pension and medical registers. The data with complete twin pairs enabled both the individual analyses on the associations of smoking behaviour with the risk of disability retirement due to COPD and the within-pair analyses, which were made to confirm and extend the results from the individual level analyses. 
The youngest study participants were aged $18 \mathrm{yrs}$ at the time of the baseline questionnaire, ensuring coverage of the entire working aged population. In the Finnish pension system, disability pension can be granted to persons aged 16-64 yrs with a medically confirmed illness, disease or injury which essentially restricts or prevents working. The incidence of diagnosed COPD increases strongly after the age of $60 \mathrm{yrs}$, when persons usually begin to receive an old-age pension. COPD diagnoses are thus quite rare among disability pensions granted to persons under the age of $60 \mathrm{yrs}$. However, since all applications for disability pension must contain information about the medical status (including the COPD stages), the pulmonary function indices and the effect of medication and other treatment, the diagnosis made by the treating specialist and confirmed by the insurance physician in connection with the grant of disability pension is reliable and consistent with the real status of the applicant.

A recent study among German male construction workers showed that smoking habits are associated with increased risk of occupational disability due to respiratory diseases: the HR for heavy smokers was 3.26 compared to never-smokers and no increased risk of disability pension due to respiratory diseases was found for moderate smokers [12]. Our results showed significantly stronger associations between smoking behaviour and disability retirement due to COPD. The possibility to analyse not only the main disease groups, such as respiratory diseases, but also specific diagnoses such as COPD should be seen as a clear strength of our study.

A further issue related to the association of cigarette smoking and COPD is whether exposure to environmental smoke (passive smoking) among never-smokers would have influenced the results $[32,34]$. Although we did not measure such exposure, it was controlled in our discordant twin analysis concerning exposure during childhood and adolescence; for example through parental smoking. Moreover, if such a "passive smoking effect" existed, it would have attenuated the risk estimates for "active" smokers.

With respect to exposure, smoking status and behaviour were assessed only at one point. Thus, we did not control for changes of smoking behaviour between exposure and outcome assessment. We could assume possible changes in smoking patterns, such as quitting smoking as well as increasing or decreasing smoking frequency between exposure and outcome assessment [33, 35]. Possible changes in smoking behaviour during the follow-up, such as quitting and starting smoking, are likely to have attenuated the results of this study. Further studies should focus on the effect of changes in smoking behaviour on the risk of disability retirement, especially due to COPD.

Disability retirement due to COPD is likely to be treated as an early end-point. The average age of retirement due to COPD was 56.2 yrs ranging from 36.7 yrs to 64.8 yrs. Thus, the lost working years are significant. Development of COPD takes several years or decades. Thus, disability retirement due to other medical reasons before a COPD diagnosis is possible. These conditions too may be due to smoking history. Based on detailed data checking we could indeed find several cases where disability pension was granted because of some other medical reason and information about a COPD diagnosis became available only after the old-age pension had been granted.

Development of COPD can be prevented at three levels [7], they are: primary prevention, reducing and eliminating the main causal risk factor, namely tobacco smoking; secondary prevention, which focuses on screening for, or early detection of, COPD (spirometry, symptoms and combination); tertiary prevention, including management of individuals identified with COPD, treatment and/or rehabilitation which slows disease progression and diminishes adverse outcomes such as exacerbations, hospital treatments, medical costs and early exit from the labour market. Preventive measures undertaken at all these levels to avert disability retirement and other harmful consequences of tobacco smoking should receive greater emphasis.

\section{STATEMENT OF INTEREST}

None declared.

\section{ACKNOWLEDGEMENTS}

This study has been carried out as a part of the TwinKela project which is a collaboration between the Social Insurance Institution of Finland (KELA) and the Dept of Public Health, Twin Study Unit, University of Helsinki (Helsinki, Finland). We wish to acknowledge the Social Insurance Institution of Finland and the Finnish Centre for Pensions for providing the outcome data on disability pensions. The Finnish Twin Cohort Study is supported by the Academy of Finland Centre of Excellence in Complex Disease Genetics.

\section{REFERENCES}

1 Murray CJ, Lopez AD. Alternative projections of mortality and disability by cause 1990-2020: Global Burden of Disease Study. Lancet 1997; 349: 1498-1504.

2 Lopez AD, Shibuya K, Rao C, et al. Chronic obstructive pulmonary disease: current burden and future projections. Eur Respir J 2006; 27: 397-412.

3 Barnes PJ, Kleinert S. COPD - a neglected disease. Lancet 2004; 364: 564-565.

4 Buist AS, McBurnie MA, Vollmer WM, et al. International variation in the prevalence of COPD (the BOLD Study): a population-based prevalence study. Lancet 2007; 370: 741-750.

5 Halbert RJ, Isonaka S, George D, et al. Interpreting COPD prevalence estimates. What is the true burden of disease? Chest 2003; 123: 1684-1692.

6 Halpin DM, Miravittles M. Chronic obstructive pulmonary disease: the disease and its burden to society. Proc Am Thorac Soc 2006; 3: 619-623.

7 Soriano JB, Zielinski J, Price D. Screening for and early detection of chronic obstructive pulmonary disease. Lancet 2009; 74: 721-732.

8 Mannino DM, Buist AS. Global burden of COPD: risk factors, prevalence, and future trends. Lancet 2007; 370: 765-773.

9 Barnes PJ. Chronic obstructive pulmonary disease. N Engl J Med 2000; 343: 269-280.

10 Pauwels RA, Rabe KF. Burden and clinical features of chronic obstructive pulmonary disease (COPD). Lancet 2004; 364: 613-620.

11 Husemoen LL, Osler M, Godtfredsen NS, et al. Smoking and subsequent risk of early retirement due to permanent disability. Eur J Public Health 2004; 14: 86-92.

12 Claessen H, Arndt V, Drath C, et al. Smoking habits and occupational disability: a cohort study of 14,483 construction workers. Occup Environ Med 2010; 67: 84-90. 
13 Kaprio J, Koskenvuo M. Genetic and environmental factors in complex diseases: the older Finnish Twin Cohort. Twin Res 2002; 5: 358-365.

14 Kujala UM, Kaprio J, Sarna S, et al. Relationship of leisure-time physical activity and mortality: The Finnish Twin Cohort. JAMA 1998; 279: 440-444.

15 Verkasalo PK, Kaprio J, Koskenvuo M, et al. Genetic predisposition, environment and cancer incidence: a nationwide twin study in Finland, 1976-1995. Int J Cancer 1999; 83: 743-749.

16 Sarna S, Kaprio J, Sistonen P, et al. Diagnosis of twin zygosity by mailed questionnaire. Hum Hered 1978; 28: 241-254.

17 Käypä hoito, www.kaypahoito.fi/web/kh/suositukset/naytaartikkeli/tunnus/hoi06040. Date last updated: November 16, 2009. Date last accessed: February 26, 2010.

18 Säynäjäkangas O, Keistinen T, Pietinalho A. Keuhkoahtaumataudin kansainväliset hoitosuositukset - mitä ne antavat meille? [What can we gain from international guidelines for diagnosis and treatment of chronic obstructive pulmonary disease?] Suomen Lääkärilehti 2005; 60: 1667-1669.

19 Pietinalho A, Kinnula VL, Sovijärvi ARA, et al. Chronic bronchitis and chronic obstructive pulmonary disease. The Finnish Action Programme, interim report. Respir Med 2007; 101: 1419-1425.

20 Tukiainen P. Keuhkoahtaumatauti [Chronic obstructive pulmonary disease]. In: Matikainen E, Aro T, Huunan-Seppälä A, Kivekäs J, Kujala S, Tola S, eds. Toimintakyky. Arviointi ja kliininen käyttö [Functioning. Evaluation and clinical use]. Duodecim, Helsinki, 2004; pp. 202-205.

21 Harkonmäki K, Silventoinen K, Levälahti E, et al. The genetic liability to disability retirement: a 30-year follow-up study of 24,000 Finnish Twins. PloS ONE 2008; 3: e3402.

22 Kaprio J, Koskenvuo M. A prospective study of psychological and socioeconomic characteristics, health behaviour and morbidity in cigarette smokers prior to quitting compared to persistent smokers and non-smokers. J Clin Epidemiol 1988; 41: 139-150.
23 Korhonen T, Broms U, Levälahti E, et al. Characteristics and health consequences of intermittent smoking: long-term follow-up among Finnish adult twins. Nicotine Tob Res 2009; 11: 148-155.

24 Blekesaune M, Solem PE. Working conditions and early retirement. A prospective study of retirement behavior. Res Aging 2005; 27: 3-30.

25 Williams RLA. Note on robust variance estimation for clustercorrelated data. Biometrics 2000; 56: 645-646.

26 Rose RJ, Broms U, Korhonen $\mathrm{T}$, et al. Genetics of smoking behavior. In: Kim Y-K, ed. Handbook of Behavior Genetics. New York, Springer, 2009; pp 411-432.

27 Boomsma D, Bushjan A, Peltonen L. Classical twin studies and beyond. Nat Rev Genet 2002; 3: 872-882.

28 Thomas DC. Statistical Methods in Genetic Epidemiology. New York: Oxford University Press, 2004.

29 Broms U, Silventoinen K, Lahelma E, et al. Smoking cessation by socioeconomic status and marital status: the contribution of smoking behavior and family background. Nicotine Tob Res 2004; 6: 447-455.

30 Ben-Zaken Cohen S, Pare PD, Man SFP, et al. The growing burden of chronic obstructive pulmonary disease and lung cancer in women: examining sex differences in cigarette smoke metabolism. Am J Respir Crit Care Med 2007; 176: 113-120.

31 Eisner MD. Secondhand smoke and obstructive lung disease. A causal effect? Am J Respir Crit Care Med 2009; 179: 973-975.

32 Yin $\mathrm{P}$, Jiang CQ, Cheng KK, et al. Passive smoking exposure and risk of COPD among adults in China: the Guangzhou Biobank cohort study. Lancet 2007; 370: 751-757.

33 Hukkinen $\mathrm{M}$, Korhonen $\mathrm{T}$, Broms $\mathrm{U}$, et al. Long term smoking behavior patterns predicting self-reported chronic bronchitis. COPD 2009; 6: 242-249.

34 Menezes AM, Hallal PC. Role of passive smoking on COPD risk in non-smokers. Lancet 2007; 370: 716-717.

35 Hukkinen M, Kaprio J, Broms U, et al. Characteristics and consistency of light smoking: Long-term follow-up among Finnish adults. Nicotine Tob Res 2009; 11: 797-805. 